\title{
Effectiveness of proliferating tissues in combination with bovine-derived xenografts to intrabony defects of alveolar bone in dogs
}

\author{
Koushu Fujinami, Shigeki Yamamoto, Mikio Ota, Yoshihiro Shibukawa and Satoru Yamada \\ Department of Periodontology, Tokyo Dental College, Chiba 261-8502, Japan
}

(Received 13 February 2007; and accepted 13 March 2007)

\begin{abstract}
The aim of this study was to investigate the effect of proliferating tissue used in combination with bovine-derived xenograft (BDX) on the formation of new cementum and bone in dogs. Intrabony defects were treated with either BDX in conjunction with autogenous proliferating tissues (BDXplus-proliferating tissues: BDX-P group) or BDX alone (BDX-alone group). The control group received no BDX or proliferating tissues. The animals were sacrificed after 2,4 , and 8 weeks of the treatment, and tissues were histologically examined. Specimens from the control group were characterized by long junctional epithelium and little bone formation. The BDX-P group showed a statistically significant increase in new bone and cementum formation compared to the BDX-alone group $(30.9 \%$ vs. $18.7, \mathrm{p}<0.01$ and $87.8 \%$ vs. $61.8, \mathrm{p}<0.01)$. The ratio of proliferating cell nuclear antigen (PCNA)-positive cells in the newly formed connective tissue of the BDX-P group was significantly greater than that in the BDX-alone group. These findings suggest that the use of proliferating tissues in combination with BDX enhances new bone and cementum formation, offering potential as therapeutic material in periodontal regeneration.
\end{abstract}

The goal of periodontal therapy is to achieve complete and predictable regeneration of tissues lost due to infection or trauma. Regenerative therapy attempts to restore the cementum, periodontal ligament (PDL) and lost supporting structures such as diseased root surfaces (2). Various graft materials have been used successfully to treat intrabony defects. Among such graft materials, autografts and allografts are common, due to their inherent properties $(7,14,15)$. It has been suggested that bone replacement grafts provide a scaffold for host resident cells and aid regeneration via osteoinductive or osteoconductive pathways (16). A bovine-derived xenograft (BDX) (Bio-Oss ${ }^{\circledR}$ Geistlich AG, Wolhousen, Switzerland) is a deproteinized bone material often used

Address correspondence to: Dr. Koushu Fujinami, Department of Periodontology, Tokyo Dental College, 1-2-2 Masago, Mihama-ku, Chiba 261-8502, Japan

Tel: +81-43-270-3954, Fax: +81-43-270-3955

E-mail: kfujinam@tdc.ac.jp in sinus-lifting and ridge-augmentation procedures, as well as in management of bone defects adjacent to teeth and implants. Bio-Oss undergoes a low-heat $\left(300^{\circ} \mathrm{C}\right)$ chemical process to extract organic components, leaving the architecture of the bone intact (8). When evaluating parameters such as inner surface area, crystallite size, or calcium-to-phosphorus ratio, Bio-Oss most closely resembles human cancellous bone (24). It is a deproteinated porous bone with a naturally occurring mineral phase and a 3-dimensional configuration that favors angiogenesis and bone formation (18). It is claimed that Bio-Oss acts as a scaffold in bone formation $(4,23)$, and that it has osteoconductive properties $(9,12)$. Since all organic components have been removed, such grafts do not elicit any allergic reaction, and are very well tolerated clinically (5). However, treating intrabony defects with BDX is only feasible with 2- or 3-wall bony defects, and is not effective in improving closure in advanced intrabony defects. Periodontal diseases result in different types of angular bone de- 
fect. The angular bone defects are classified on the basis of the number of osseous walls, which is one, two, or three in number.

Proliferating tissues underlying the barrier membrane in periodontal osseous defects possess diverse growth factors, and they are believed to be involved in the early stage of the wound-healing process (10). Amar et al. (1) investigated the distribution of matrix macromolecules in the proliferating tissues in periodontal osseous defects under a barrier membrane, and detected positive reactions to major matrix macromolecules. Sugimoto et al. (22) reported that proliferating tissues induced cementum formation on a dentin block surface. Furthermore, several lines of evidence indicate that the application of proliferating tissues stimulates local bone formation $(10,22)$. These findings suggest that the application of proliferating tissues in conjunction with BDX affects wound-healing responses in the periodontal tissues of intrabony defects.

Therefore, the purpose of this study was to determine the effects of local application of proliferating tissues as an adjunct to BDX treatment on periodontal tissue regeneration in intrabony defects.

\section{MATERIALS AND METHODS}

Twelve beagle dogs were used in this study. All experiments were performed according to the Guidelines for the Treatment of Experimental Animals at Tokyo Dental College. The animals were placed under general anesthesia with ketamine hydrochloride at a dosage of $10 \mathrm{mg} / \mathrm{kg}$.

Preparation of the proliferating tissues. Proliferating tissues were prepared as follows: periodontal osseous defects were created around maxillary ${ }_{2} \mathrm{P}_{2}$ (Fig. 1) to induce tissue growth under the membrane to be placed. The defect was covered with an expanded polytetrafluoroethylene (e-PTFE) membrane (GTAM Ovl-9; WL Gore \& Associates, Flagstaff, AZ). The flaps were then replaced and sutured. This method of inducing proliferation in transplanted proliferating tissue has been described previously by Sugimoto et al. (22). Two weeks after this procedure, a reentry surgical procedure was performed at the same site to remove the membranes and retrieve the proliferating tissue. This proliferating tissue was transplanted to the bone defects of the same individual.

Surgical procedure. Experimental surgery involved elevating the buccal and lingual mucoperiosteal flaps to create "box-type", two-wall intrabony defects $(5 \times 5 \times 5 \mathrm{~mm})$ at the distal aspect of the second, and the mesial aspect of the fourth, mandibular premolars in either the right or left jaw quadrants. To prevent spontaneous healing and enhance plaque accumulation, rubber base impression material was placed in each defect. At 12 weeks following creation of the defects, the flaps were raised, the rubber base impression material was removed from each defect, granulation tissue resulting from inflammation was removed, and the root surfaces facing the defects were scaled and planed. Using a small round burr, reference notches indicating the bottom of the defect were prepared on the root surfaces. The intrabony defects were then randomly assigned to one of the following 3 treatment groups $(5$ sites in each group): BDX-alone group, a combined therapy with BDX-P group, and a control group which received neither treatment. An amount of BDX sufficient to fill the intrabony defect was mixed with the proliferating tissues $(100-200 \mathrm{mg}$ ), and the BDX/proliferating tissue mixture was allowed to sit for about $10 \mathrm{~min}$, after which, it was packed into the intrabony defect. The gingival flaps were secured with interdental sutures to obtain coverage of the surgical site. At weeks 2, 4 and 8 postoperatively, the animals were euthanized by intravenous injection with an overdose of sodium pentobarbital. The specimens containing the experimental tissues were placed in $10 \%$ buffered formalin and decalcified with $10 \%$ ethylenediamine tetraacetic acid (EDTA) (Wako, Tokyo, Japan). They were then dehydrated in ethanol, embedded in paraffin, serially sectioned (at $5 \mu \mathrm{m}$

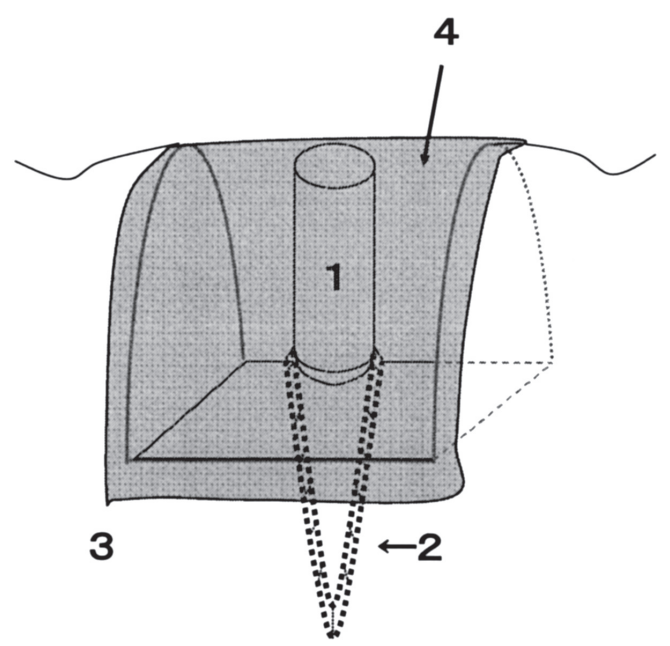

Fig. 1 Schema of periodontal osseous defect. 1: Root, 2: periodontal ligament, 3: alveolar bone, 4: e-PTFE membrane. 
thickness) in a buccolingual orientation, and then stained with hematoxylin and eosin.

Histomorphometric analysis. Five sections were used from each root for microscopic examination and histometric assessment at 8 weeks after surgery. Two quantitative parameters were evaluated: first, in order to determine the percentage of newly-formed cementum, the cross-sectional length of new cementum was divided by the cross-sectional length of the original defect (apical notch to cemento-enamel junction); next, the proportion of the total area of new bone (bone fill) or BDX particles (BDX fill) to the total area of the original two-wall intrabony defect, and the proportion of the cross-sectional area of new bone or BDX particles to the cross-sectional area of the intrabony defect were calculated. These measurements were statistically analyzed using the Scheffe test $(n=5)$ to determine whether there were any significant differences among the tested histometric parameters.

Immunohistochemistry for PCNA. Immunohistochemical staining for proliferating cell nuclear antigen (PCNA) at 2-postoperative week was performed with an Immunoperoxidase Staining Kit (Histofine SAB-PO (M) kits; Nichirei, Tokyo, Japan). The sections were incubated with mouse PCNA primary antibody (PC-10; DAKO Corporation Carpinteria, CA, USA) at a dilution of $1: 100$. The sections were then incubated with biotinylated secondary antibody and streptavidin peroxidase reagents. The presence of peroxidase complexes was visualized by 3,3'diaminobenzidine tetrahydrochloride $(0.1 \mathrm{mg} / \mathrm{mL})$ solution with $0.65 \% \mathrm{H}_{2} \mathrm{O}_{2}$. Sections were counterstained with Mayer's hematoxylin. Histometric analyses were performed microscopically at a magnification of $\times 400$, after the specimens were randomly numbered such that the examiner did not know their identity. The numbers of PCNA-positive cells were counted in the area of connective tissue in the two-wall intrabony defect. An analysis of variance and the multiple comparison Scheffe test were used to analyze the data.

\section{RESULTS}

Control group (8 weeks after surgery)

The long, junctional epithelium was found apically along the root surface. The defects were partly filled with new bone. Although there was an increase in new bone tissue at the base of the defect, there was no bone on the root surface of the coronal portion.

\section{Experimental groups}

At 2 weeks after surgery, most of the implanted BDX particles remained within the defect in the BDX-P group (Fig. 2a). Bone tissue sometimes connected with BDX particles, creating a bridged network of small islands (Fig. 2b). The trabecular bone regeneration appeared more extensive apically than coronally. In all sites where proliferating tissues were applied (BDX-P group), more regeneration of trabecular bone was observed than in the control sites. At this stage, no new cementum formation was observed. In the BDX-alone group, the specimens showed inflammatory infiltrates and hemorrhages throughout the entire area (Fig. 3a). Most of the implanted porous BDX granules remained within the defects and were surrounded by loose fibrous tissue (Fig. 3b). At this point, new bone formation was observed only at the base of the defects.

At 4 weeks after surgery, bone regeneration in the BDX-P group was more extensive (Fig. 2c). Some porous BDX particles at the base of the defects were surrounded by new bone tissue or completely encased in bone tissue, while the others in the upper part of the defects were surrounded by connective tissue (Fig. 2c). At this stage, new cementum formation was clearly observed (Fig. 2d). The layer of new cementum was thicker in the apical portion of the root surface. In the BDX-alone group, the defects were partly filled with new bone (Fig. 3c). Although an increase in new bone tissue was observed on the BDX particles near the walls, none was observed on the root surfaces. As a result, angular bony defects were still present and occupied by loose fibrous tissue (Fig. 3c). Newly formed cementum was present in the notch of the root surface, but no new cementum formation was observed in the other regions (Fig. 3d).

At 8 weeks after surgery, new bone and cementum formation had occurred in both the BDX-P and the BDX-alone groups, as summarized in Table 1. The amount of new cementum was $87.8 \pm 1.1 \%$ in the BDX-P group, and $61.8 \pm 13.4 \%$ in the BDXalone group. New bone gains in the BDX-P group and BDX-alone group were $30.9 \pm 4.9 \%$ and $87.8 \pm$ $1.1 \%$, respectively. These differences were statistically significant $(p<0.01)$. The percentage of the mean BDX fill was $9.3 \pm 3.1 \%$ in the BDX-P group and $12.5 \pm 2.1 \%$ in the $\mathrm{BDX}$-alone group, providing no statistically significant difference.

In the BDX-P group, most of the defects were completely filled with porous BDX particles which were surrounded by new bone (Fig. 2e). The amount of bone observed was much greater than that in the 

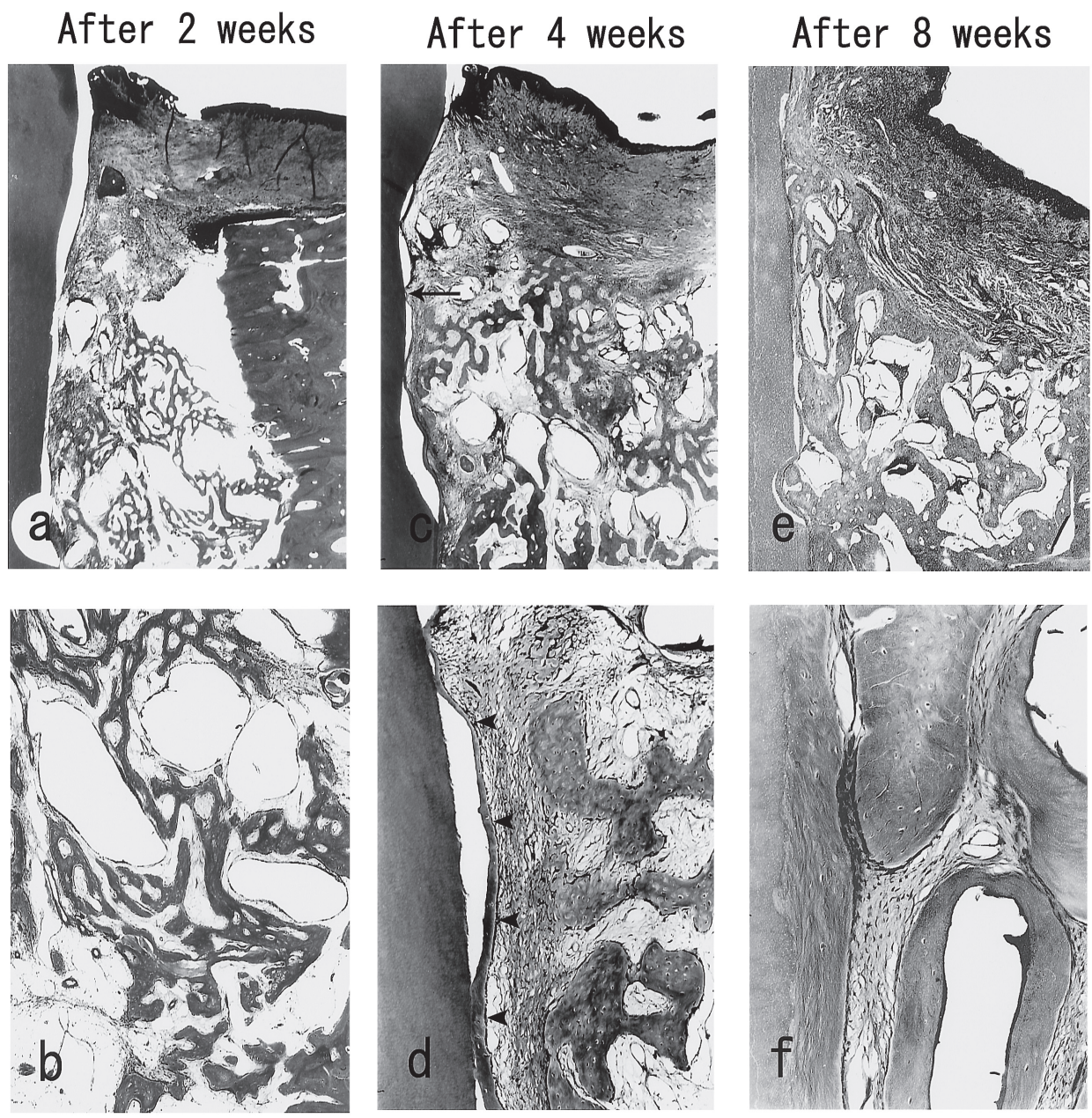

Figs. 2 and 3 Histology of periodontal healing area after BDX with or without proliferating tissues (hematoxylin and eosin staining). Fig. 2: BDX-P group. Fig. 3: BDX-alone group. At 2 weeks after surgery (Fig. 2a, 3a), new bone tissue sometimes connected with BDX granules (Fig. 2b). On the other hand, most porous BDX were surrounded by lose fibrous tissue (Fig. 3b). At 4 weeks after surgery (Fig. 2c, 3c), new cementum formation (arrows) was clearly observed (Fig. 2d). On the other hand, new cementum (arrowheads) was present only in notch of root surface (Fig. 3d). Arrows indicate coronal portion of newly formed cemutum in Figs. 2c and 3c. At 8 weeks after surgery (Fig. 2e, 3e), new cementum and bone formation in BDX-P group were significantly greater than that of BDX-alone group. New alveolar bone and periodontal ligament developed coronally to apical notch (Fig. 2f). On the other hand, newly-formed cementum and periodontal ligament were present in notch of root surface (Fig. 3f). (original magnification a, c, and $e \times 5$; b, d, and $f \times 50$ ).

4-week specimens (Fig. 2c). In all specimens, a thin layer of new cementum was observed along the root surface (Fig. 2f). Newly formed periodontal ligament space was observed between the newly formed bone and cementum (Fig. 2e). In the BDX-alone group, some BDX particles at the base of the defects were surrounded by new bone (Fig. 3e), while others in the middle and upper parts of the defects were surrounded by dense connective tissue (Fig. 3e), and newly formed periodontal ligament was present only at the notch of the root surface (Fig. 3f). In all sites where proliferating tissues were applied (BDX-P group), more periodontal ligament with new cemen- tum and bone formation were observed than in the control sites (BDX-alone group).

\section{Immunohistochemistry for PCNA}

Results indicating the number of PCNA-positive cells in the newly formed connective tissue of the BDX-P and BDX-alone groups are summarized in Table 2. The ratio of PCNA-positive cells in the BDX-P and BDX-alone groups after two weeks were $32.8 \pm 3.4$ and $9.5 \pm 3.2$, respectively, and the difference was statistically significant $(\mathrm{p}<0.01)(\mathrm{Ta}-$ ble 2). 

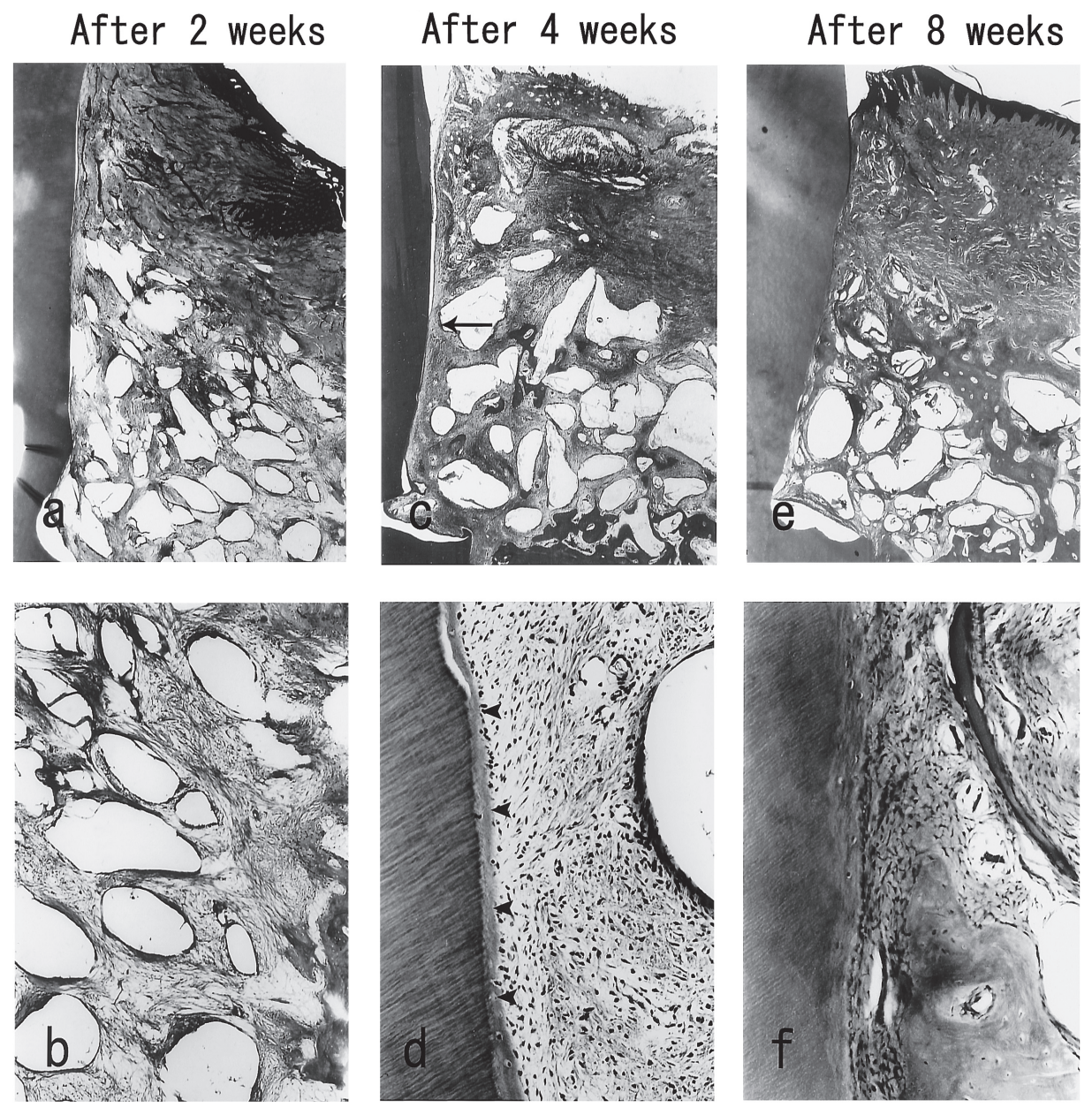

Fig. 3

\section{DISCUSSION}

In this study, we investigated whether proliferating tissues applied to intrabony defects in BDX-based treatment enhanced periodontal regeneration. We found that application of proliferating tissues in conjunction with BDX induced significantly higher periodontal regeneration in comparison with application of BDX alone, but neither ankylosis or root resorption.

Various studies have suggested a correlation between defect morphology of alveolar bone and regenerative results $(6,11)$. Clinically, an intraosseous component depth of more than $4 \mathrm{~mm}$ is being seen with increasing frequency, and defect volume is an important factor in determining wound-healing outcomes. More favorable healing responses have been reported in 3-wall intrabony defects than in 1-or 2 -wall intrabony defects $(3,19)$. Three-wall intrabony defects provide a high predictability of out- comes in regenerative procedures, while no or lower potential of growth and differentiation factors in this intrabony defects provide a suitable testing model for regenerative efficacy and the most frequently encountered wound-healing situations (17). In this study, we used box-type, 2-wall intrabony defects $(5 \times 5 \times 5 \mathrm{~mm})$. In the control group, a small amount of periodontal regeneration was detected around the notch on the root surface, while in the BDX-alone group, new bone and cementum showed a significant increase (Table 1). These results indicated that in the 2-wall intrabony defects, connective tissues entered the bone defect with spontaneous healing, preventing undifferentiated cell growth, and immature granulation tissues containing growth factors were removed from the periodontal defects during the wound-healing period. Clinically, pure 3-wall defects are rare. Selvig et al. (21) reported that the percentage of 3-wall defects was less than $30 \%$, and that the most common occlusal component was a 
Table 1. Histometric parameters (mean, standard deviation, and range [\%]) for each surgical treatment

\begin{tabular}{|c|c|c|c|c|}
\hline & BDX-plus-proliferating tissue & & BDX-alone & Control \\
\hline & mean $\pm \mathrm{SD}(\%)$ & & mean $\pm \mathrm{SD}(\%)$ & mean $\pm \mathrm{SD}(\%)$ \\
\hline New cementum & $87.8 \pm 1.1$ & $*$ & $-61.8 \pm 13.4$ & $34.5 \pm 2.5$ \\
\hline New bone & $\begin{array}{c}{ }^{30.9} \pm 4.9 \\
\llcorner\end{array}$ & $*$ & 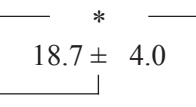 & $5.1 \pm 2.7$ \\
\hline BDX & $9.3 \pm 3.1$ & NS & $12.5 \pm 2.1$ & \\
\hline
\end{tabular}

Statistically significant: $* \mathrm{p}<0.01(\mathrm{n}=5)$

No statistically significant difference: NS

Table 2. Ratio of PCNA-positive cells in gingival connective tissue

\begin{tabular}{|c|c|c|}
\hline & BDX-plus-proliferating tissue & BDX-alone \\
\hline & mean $\pm \mathrm{SD}$ & mean $\pm \mathrm{SD}$ \\
\hline PCNA-positive cells & $32.8 \pm 3.4$ & $9.5 \pm 3.2$ \\
\hline
\end{tabular}

Statistically significant: ${ }^{*} \mathrm{p}<0.01(\mathrm{n}=5)$

combination of 1- and 2-wall configurations.

Sugimoto et al. (22) reported histological observations on proliferating tissues applied to dentin block transplantation in the early wound-healing stage. That study showed an increase in undifferentiated mesenchymal cells in proliferating tissues which differentiated into osteoblasts and cementoblasts, resulting in enhanced potential for desirable periodontal tissue regeneration. In the present study, BDX fill has been shown to be $9.35 \%$ in the BDX-P group as compared to $12.5 \%$ in the $\mathrm{BDX}$-alone group, providing no statistically significant difference. Though, the amount of new bone and new cementum formed in the BDX-P group $(30.9 \%$ and $87.8 \%$, respectively) was larger than that in the BDX-alone group $(18.7 \%$ and $61.8 \%$, respectively) $(\mathrm{p}<0.01)$ (Table 1). Immunohistologically, PCNApositive cells were detected in the granulation tissue on 2 weeks after surgery (Table 2), slightly decreasing 4 weeks after surgery (data not shown). These results suggest that proliferating tissue application accelerates local inflammatory responses in the early wound-healing stage, stimulating resident cells in remaining periodontal tissues, and affecting periodontal regeneration in the proliferating tissue-applied region. Cytokines and growth factors have been detected in proliferating tissues $(1,10,22)$. Katayama et al. (10) reported that expression of bFGF and alkaline phosphatase (ALP) mRNA increased in proliferating tissues. It has been reported that $\mathrm{bFGF}$, which is a potent mitogen of undifferentiated cells, including bone cells and periodontal ligament cells, stimulates osteogenic expression of stromal bone marrow cells in rats. It has been shown that BDX in combination with enamel matrix derivative (EMD) enhances bone fill in intrabony defects $(13,20)$. It appears that the scaffold and osteoconductive properties associated with BDX play a positive role in new bone formation associated with regenerative procedures. These findings suggest that intrabony defects can be effectively treated through utilization of the combination of the osteoconductive properties of $\mathrm{BDX}$ and the cytokines of proliferating tissues involved in different operates at different stages of periodontal regeneration.

The results of this study suggest that application of proliferating tissues as an osteopromotive agent in combination with BDX increases bone conductivity in graft materials. Furthermore, these results suggest that a combination of BDX and proliferating tissues significantly affects periodontal regeneration in wider bone defects, and that more effective healing is obtainable by this method than with graft material alone.

\section{REFERENCES}

1. Amar S, Petrungaro P, Amar A and Van Dyke TE (1995) Immunolocalization of bone matrix macromolecules in human tissues regenerated from periodontal defects treated with expanded polytetrafluoroethylene membranes. Arch Oral Biol 
40, 653-661.

2. American Academy of Periodontology (2001) Glossary of Periodontal Terms, 4th ed., p44, American Academy of Periodontology, Chicago.

3. Becker W and Becker BE (1993) Treatment of mandibular 3-wall intrabony defects by flap debridement and expanded polytetrafluoroethylene barrier membranes. Long-term evaluation of 32 treated patients. J Periodontol 64, 1138-1144.

4. Berglundh T and Lindhe J (1997) Healing around implants placed in bone defects treated with Bio-Oss. An experimental study in the dog. Clin Oral Implants Res 8, 117-124.

5. Camelo M, Nevins ML, Schenk RK, Simion M, Rasperini G, Lynch SE and Nevins M (1998) Clinical, radiographic, and histologic evaluation of human periodontal defects treated with Bio-Oss and Bio-Gide. Int $J$ Periodontics Restorative Dent 18, 321-331.

6. Cortellini P and Tonetti MS (2000) Focus on intrabony defects: guided tissue regeneration. Periodontol 2000 22, 104 132.

7. Garrett S (1996) Periodontal regeneration around natural teeth. Ann Periodontol 1, 621-666.

8. Gross JS (1997) Bone grafting materials for dental applications: a practical guide. Compend Contin Educ Dent 18, 1013-1018, 1020-1022, 1024, passim; quiz. Review.

9. Hurzeler MB, Quinones CR, Kirsch A, Gloker C, Schupbach P, Strub JR and Caffesse RG (1997) Maxillary sinus augmentation using different grafting materials and dental implants in monkeys. Part I. Evaluation of anorganic bovinederived bone matrix. Clin Oral Implants Res 8, 476-486.

10. Katayama A, Ota M, Sugito H, Shibukawa Y and Yamada S (2006) Effect of proliferating tissue on transplanted teeth in dogs. Oral Surg Oral Med Oral Pathol Oral Radiol Endod 101, e110-e118.

11. Klein F, Kim TS, Hassfeld S, Staehle HJ, Reitmeir P, Holle R and Eickholz P (2001) Radiographic defect depth and width for prognosis and description of periodontal healing of infrabony defects. J Periodontol 72, 1639-1646.

12. Klinge B, Alberius P, Isaksson S and Jonsson J (1992) Osseous response to implanted natural bone mineral and synthetic hydroxylapatite ceramic in the repair of experimental skull bone defects. J Oral Maxillofac Surg 50, 241-249.

13. Lekovic V, Camargo PM, Weinlaender M, Nedic M, Aleksic $\mathrm{Z}$ and Kenney EB (2000) A comparison between enamel matrix proteins used alone or in combination with bovine porous bone mineral in the treatment of intrabony periodontal defects in humans. $J$ Periodontol 71, 1110-1116

14. Mellonig JT (1984) Decalcified freeze-dried bone allograft as an implant material in human periodontal defects. Int J Periodontics Restorative Dent 4, 40-55.

15. Mellonig JT, Bowers GM and Bailey RC (1981) Comparison of bone graft materials Part II. A histological evaluation. $J$ Periodontol 52, 297-302.

16. Mellonig JT, Bowers GM and Cotton WR (1981) Comparison of bone graft materials. Part I. New bone formation with autografts and allografts determined by strontium-85. J Periodontol 52, 291-296.

17. Paolantonio M (2002) Combined periodontal regenerative technique in human intrabony defects by collagen membranes and anorganic bovine bone. A controlled clinical study. J Periodontol 73, 158-166.

18. Pedersen KN and Haanaes HR (1980) Further studies on tissue ingrowth into intrabony porous ceramic implants. Int $J$ Oral Surg 9, 140-143.

19. Renvert S, Garrett S, Nilveus R, Chamberlain AD and Egelberg J (1985) Healing after treatment of periodontal intraosseous defects. VI. Factors influencing the healing response. $J$ Clin Periodontol 12, 707-715.

20. Sculean A, Chiantella GC, Windisch P, Gera I and Reich E (2002) Clinical evaluation of an enamel matrix protein derivative (Emdogain) combined with a bovine-derived xenograft (Bio-Oss) for the treatment of intrabony periodontal defects in humans. Int J Periodontics Restorative Dent 22, 259-267.

21. Selvig KA, Kersten BG and Wikesjo UM (1993) Surgical treatment of intrabony periodontal defects using expanded polytetrafluoroethylene barrier membranes: infuence of defect configuration on healing response. J Periodontol 64, 730 733.

22. Sugimoto S, Ota M, Shibukawa Y and Yamada S (2004) Formation of new periodontal ligament around transplanted teeth proliferating tissue in periodontal osseous defect under barrier membrane. Biomed Res 25, 179-187.

23. Thaller SR, Hoyt J, Dart A, Borjeson K and Tesluk H (1994) Repair of experimental calvarial defects with Bio-Oss particles and collagen sponges in a rabbit model. $J$ Craniofac Surg 5, 242-246.

24. Valdre G, Mongiorgi R, Ferrieri P, Corvo G, Cattaneo V, Tartaro G (1995) Scanning electron microscopy and microanalysis applied to the study of biomaterials for dental use. Minerva Stomatologica 44, 55-68. (in Italian) 
